\title{
Commentary Snail in the frame of malignant tumor recurrence
} Bram De Craene and Geert Berx

Unit of Molecular and Cellular Oncology, Department for Molecular Biomedical Research, VIB-Ghent University, Belgium

Corresponding author: Geert Berx, geert.berx@dmbr.UGent.be

Published: 5 July 2006

This article is online at http://breast-cancer-research.com/content/8/4/105 (c) 2006 BioMed Central Ltd
Breast Cancer Research 2006, 8:105 (doi:10.1186/bcr1521)

cutaneously in mice showed rapid recurrence upon inactivation of the HER2/neu pathway, which indicates that Snail contributes functionally to tumor recurrence in vivo.

Snail plays an important role in the epithelial-to-mesenchyma transition during development and in tumor progression. Induction of Snail expression coincides with drastic morphological changes in cultured epithelial cells. Recently, a new role for Snail in tumor recurrence has been inferred from a reversible HER-2/neu-induced breast cancer mouse model. Comparative transcriptome analysis of human primary breast cancers suggests that elevated Snail expression is correlated with decreased relapse-free survival. Further characterization of Snail as master regulator in this process might enhance our understanding of the molecular and cellular changes during and after breast tumor recurrence.

Early detection of breast cancer is crucial for the survival of breast cancer patients. However, for unknown reasons almost a quarter of patients with breast cancer without overt lymph node metastases suffer metastatic relapse within 10 years post-surgery. To increase survival, it is necessary to improve treatment and prevent recurrence. This requires a more thorough understanding of the molecular basis of breast cancer recurrence.

In Cancer Cell, Moody and colleagues [1] described the spontaneous up-regulation of the transcription factor Snail in recurrent breast tumors in a transgenic mouse model. In this model, tetracycline-inducible HER2/neu expression is targeted to the mammary gland by the mammary specific expression of the reverse TET transactivator (rtTA). Withdrawal of tetracycline inactivates HER2/neu expression, resulting in remarkable regression of breast tumors. Surprisingly, most recurrences were accompanied by an epithelial-to-mesenchymal transition (EMT), a form of phenotypic and functional plasticity that occurs spontaneously during tumor progression. Once the tumor achieves the dedifferentiated stage of single-cell dissemination, metastasis accelerates and prognosis worsens [2]. Microarray analysis of these particular tumor recurrences showed strong up-regulation of the transcription factor Snail, a key player in EMT. Primary breast cancer cells transduced with Snail and grafted sub-
Snail family members encode zinc-finger transcription factors that are organized similarly: they are composed of a highly conserved carboxy-terminal region that binds E-box consensus sequences in target promoters, and a much more divergent amino-terminal region. The vertebrate Snail genes code for both Snail and Slug proteins [3]. The finding that Snail can repress the expression of the invasion-suppressor protein E-cadherin was important evidence linking Snail to cancer [4,5]. E-cadherin is a $\mathrm{Ca}^{2+}$-dependent cell-cell adhesion protein that performs important functions during embryogenesis and during morphogenesis of adult tissues, as it is necessary in the formation of cell polarity in epithelial cell differentiation [6]. In a variety of human carcinoma types, loss of E-cadherin is associated with dedifferentiation, invasion and metastasis [7].

Snail appears to act as a master regulator, repressing the epithelial phenotype by affecting the transcription of many genes implicated in the specific structure of the epithelial cell [8]. During development of Drosophila, Snail has an intimate relationship with Twist, a basic helix-loop-helix (bHLH) factor. Twist functions as a positive regulator of mesoderm-specific genes, and Snail acts as repressor of ectodermal genes, and together they define the borders of the mesoderm and the surrounding tissue [9]. In human mammary tumor progression, this cooperation might be supplanted by independence, with Twist linked to metastasis [10] and Snail to recurrence [1].

This finding demands a plausible explanation of how tumor recurrence acquires this apparent Snail expression. Putatively, the dramatic tumor regression that follows inactivation of the oncogene neu would result in a temporary situation in which the primary tumor site becomes highly activated, as in post-

$\mathrm{EMT}=$ epithelial-to-mesenchymal transition. 


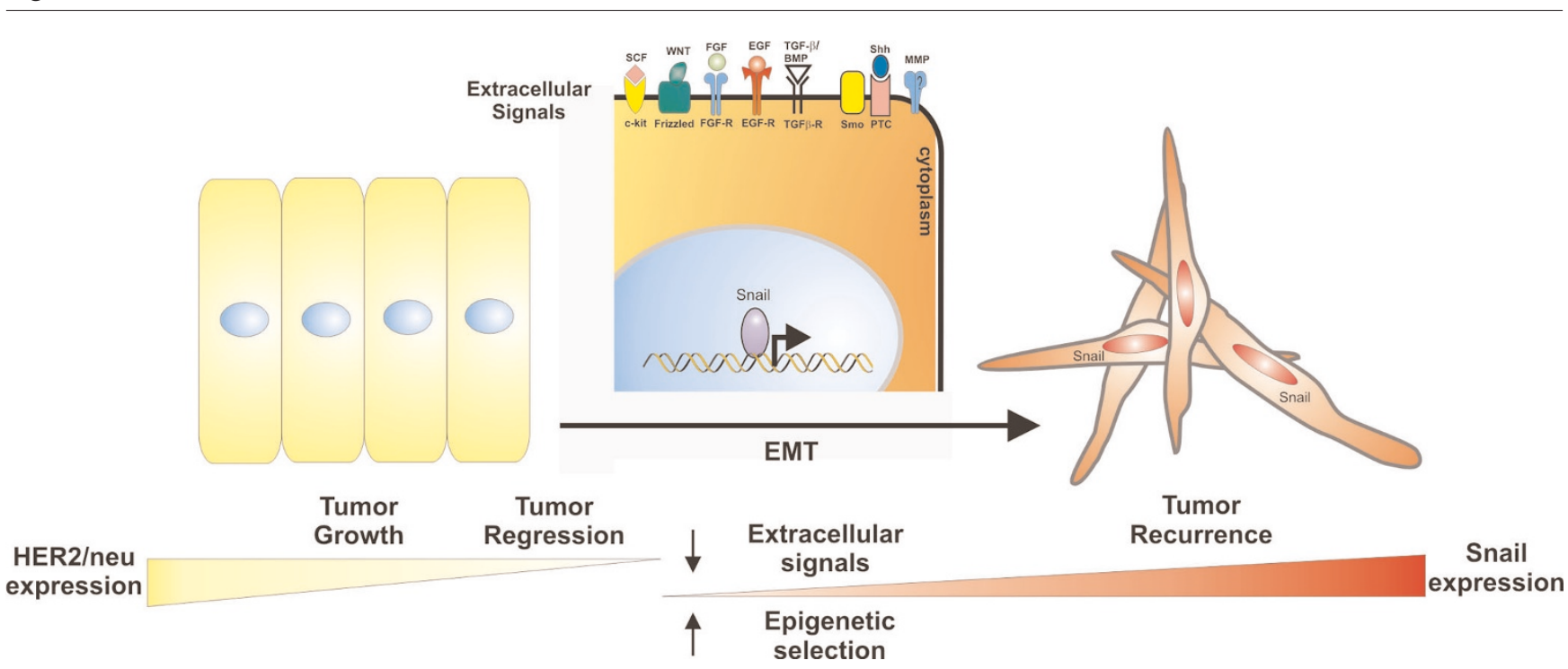

Schematic of local cancer recurrence in a reversible HER2/neu mouse model. Inactivation of HER2/neu expression results in the regression of breast tumors. Both epigenetic selection and a cocktail of extracellular signals can establish a population of Snail expressing cells allowing epithelial-to-mesenchymal transition and survival, eventually leading to mesenchymal recurrences. BMP, bone morphogenetic protein; EGF(-R), epidermal growth factor (-receptor); FGF(-R), fibroblast growth factor (-receptor); MMP, matrix metalloproteinase; PTC, patched; SCF, stem cell factor; Shh, sonic hedgehog; Smo, smoothened; TGF- $\beta(-\mathrm{R})$, transforming growth factor beta (-receptor); WNT, member of the Wnt family of peptide ligands.

surgical wounds. It has been shown that wound-drainage fluid taken after breast cancer surgery stimulated proliferation of different breast cancer cell lines [11]. Consistent with this finding, it is generally accepted that EMT can be induced by a variety of growth factors, such as epidermal growth factor, fibroblast growth factor, hepatocyte growth factor and transforming growth factor- $\beta$; furthermore, it has been reported that the expression of Snail family members is downstream from these pathways [12] (Figure 1).

Going one step further, one might speculate that Snail has a role in allowing the self-maintenance of the early pool of recurrent cells. It has been shown that Snail can induce DeltaEF1 [13], another transcriptional repressor of E-cadherin regulating epithelial plasticity in breast cancer cells [14]. Besides its role as repressor of the epithelial phenotype, Snail acts as a survival factor. In fact, upregulation of Snail could be a rapidly induced epigenetic variation aimed at genetically inhibiting cell death. Indeed, expression of Snail seems to protect cells from caspasemediated programmed cell death elicited by serum depletion or by signals downstream of therapeutic agents, tumor necrosis factor- $\alpha$ and DNA damage $[15,16]$. In this context it is worth mentioning that the highly homologous Slug seems to be a target gene of p53 and acts as an antagonist of PUMA (p53-upregulated modulator of apoptosis) [17]. Snail can repress KLF4 [8], a tumor suppressor that can repress p53 levels and simultaneously induce p21 CIP1 [18]. Pointing in the same direction are the data from conditional hypomorphic Snail expression in mice, in which resistance to radiation and to formation of spontaneous epithelial and mesenchymal tumors is increased [19].

By reanalyzing existent microarray expression data sets, Chodosh and colleagues [1] also show that Snail expression could have predictive value for recurrence in subsets of primary human breast cancers. Although the value of gene signatures predictive of breast cancer recurrence is heavily debated, it should also be noted that the original research papers never suggested that Snail is of key importance for the identified metastasis signatures. Furthermore, in their analysis, Snail expression could not be associated with two important prognostic markers: tumor size and lymph node status. This is unexpected, because the role of Snail as a repressor of the epithelial differentiated state argues that it would promote disease progression. An interesting question is whether these local mesenchymal outgrowths result in a more pronounced metastatic phenotype in the mouse, which would be representative of recurrence in humans.

The importance of these new insights, in our opinion, should be viewed with care, as interpreting the expression levels of Snail mRNA is cumbersome: elevated cellular expression of Snail could be due to stromal contamination, and low expression could become diluted in the whole of a tumor extract. Furthermore, expression at the mRNA level does not necessarily mean nuclear functional activity, because Snail could be localized in the cytoplasm. The need for highly 
efficient antibodies that allow evaluation of the protein expression status are essential for understanding the interesting connection between HER-2/neu, Snail and EMT as a real functional marker for breast cancer recurrence, which could then generate new ways for rational therapeutic intervention.

\section{Competing interests}

The authors declare that they have no competing interests.

\section{References}

1. Moody SE, Perez D, Pan TC, Sarkisian CJ, Portocarrero CP, Sterner CJ, Notorfrancesco KL, Cardiff RD, Chodosh LA: The transcriptional repressor Snail promotes mammary tumor recurrence. Cancer Cell 2005, 8:197-209.

2. Thiery JP: Epithelial-mesenchymal transitions in tumour progression. Nat Rev Cancer 2002, 2:442-454.

3. Nieto MA: The snail superfamily of zinc-finger transcription factors. Nat Rev Mol Cell Biol 2002, 3:155-166.

4. Batlle E, Sancho E, Franci C, Dominguez D, Monfar M, Baulida J, Garcia De Herreros A: The transcription factor snail is a repressor of E-cadherin gene expression in epithelial tumour cells. Nat Cell Bio/ 2000, 2:84-89.

5. Cano A, Perez-Moreno MA, Rodrigo I, Locascio A, Blanco MJ, del Barrio MG, Portillo $F$, Nieto MA: The transcription factor snail controls epithelial-mesenchymal transitions by repressing $\mathrm{E}$ cadherin expression. Nat Cell Biol 2000, 2:76-83.

6. Strumane K, van Roy F, Berx G: The role of E-cadherin in epithelial differentiation and cancer progression. Recent Res Devel Cell Biochem 2003, 1:33-77.

7. Berx G, Nollet F, van Roy F: Dysregulation of the E-cadherin/ catenin complex by irreversible mutations in human carcinomas. Cell Adhes Commun 1998, 6:171-184.

8. De Craene B, Gilbert B, Stove C, Bruyneel E, van Roy F, Berx G: The transcription factor snail induces tumor cell invasion through modulation of the epithelial cell differentiation program. Cancer Res 2005, 65:6237-6244.

9. Alberga A, Boulay JL, Kempe E, Dennefeld C, Haenlin M: The snail gene required for mesoderm formation in Drosophila is expressed dynamically in derivatives of all three germ layers. Development 1991, 111:983-992.

10. Yang J, Mani SA, Donaher JL, Ramaswamy S, Itzykson RA, Come C, Savagner P, Gitelman I, Richardson A, Weinberg RA: Twist, a master regulator of morphogenesis, plays an essential role in tumor metastasis. Cell 2004, 117:927-939.

11. Tagliabue $E$, Agresti $R$, Carcangiu ML, Ghirelli C, Morelli $D$, Campiglio M, Martel M, Giovanazzi R, Greco M, Balsari A, Menard S: Role of HER2 in wound-induced breast carcinoma proliferation. Lancet 2003, 362:527-533.

12. De Craene B, van Roy F, Berx G: Unraveling signalling cascades for the Snail family of transcription factors. Cell Signal 2005, 17:535-547.

13. Guaita S, Puig I, Franci C, Garrido M, Dominguez D, Batlle E, Sancho E, Dedhar S, De Herreros AG, Baulida J: Snail induction of epithelial to mesenchymal transition in tumor cells is accompanied by MUC1 repression and ZEB1 expression. J Biol Chem 2002, 277:39209-39216.

14. Eger A, Aigner $\mathrm{K}$, Sonderegger S, Dampier B, Oehler S, Schreiber M, Berx G, Cano A, Beug H, Foisner R: DeltaEF1 is a transcriptional repressor of $\mathrm{E}$-cadherin and regulates epithelial plasticity in breast cancer cells. Oncogene 2005, 24:23752385.

15. Kajita M, McClinic KN, Wade PA: Aberrant expression of the transcription factors snail and slug alters the response to genotoxic stress. Mol Cell Biol 2004, 24:7559-7566.

16. Vega S, Morales AV, Ocana OH, Valdes F, Fabregat I, Nieto MA: Snail blocks the cell cycle and confers resistance to cell death. Genes Dev 2004, 18:1131-1143.

17. Wu WS, Heinrichs S, Xu D, Garrison SP, Zambetti GP, Adams JM, Look AT: Slug antagonizes p53-mediated apoptosis of hematopoietic progenitors by repressing puma. Cell 2005, 123:641-653.

18. Rowland BD, Bernards R, Peeper DS: The KLF4 tumour suppressor is a transcriptional repressor of p53 that acts as a contextdependent oncogene. Nat Cell Biol 2005, 7:1074-1082.
19. Perez-Mancera PA, Perez-Caro M, Gonzalez-Herrero I, Flores T, Orfao A, de Herreros AG, Gutierrez-Adan A, Pintado B, Sagrera A, Sanchez-Martin M, Sanchez-Garcia I: Cancer development induced by graded expression of Snail in mice. Hum Mol Genet 2005, 14:3449-3461. 